\title{
Erratum to: Comments on the Dynamic Analysis of V-Shaped Atomic Force Microscopy in Liquid Environment by Considering Timoshenko Beam Theory
}

\author{
M. Damircheli • M. H. Korayem
}

Published online: 7 August 2014

(C) King Fahd University of Petroleum and Minerals 2014

Erratum to: Arab J Sci Eng

DOI 10.1007/s13369-014-1296-Z

The original version of this article unfortunately contained a mistake. The sequence of the author name was incorrect. The correct order is given here.

The online version of the original article can be found under doi:10.1007/s13369-014-1296-z.

M. Damircheli · M. H. Korayem ( $\varangle)$

Department of Mechanical and Aerospace Engineering, Science and Research Branch, Islamic Azad University, Tehran, Iran e-mail: hkorayem@iust.ac.ir

M. H. Korayem

Robotic Research Laboratory, School of Mechanical Engineering,

Iran University of Science and Technology, Tehran, Iran 